\title{
BMJ Open Hilly environment and physical activity among community-dwelling older adults in Japan: a cross-sectional study
}

\author{
Takafumi Abe (i) , ${ }^{1}$ Kenta Okuyama, ${ }^{1,2}$ Tsuyoshi Hamano, ${ }^{1,3}$ Miwako Takeda, \\ Minoru Isomura, ${ }^{1,4}$ Toru Nabika ${ }^{1,5}$
}

To cite: Abe T, Okuyama $\mathrm{K}$, Hamano $\mathrm{T}$, et al. Hilly environment and physical activity among communitydwelling older adults in Japan: a cross-sectional study. BMJ Open 2020;10:e033338. doi:10.1136/ bmjopen-2019-033338

- Prepublication history and additional material for this paper are available online. To view these files, please visit the journal online (http://dx.doi. org/10.1136/bmjopen-2019033338).

Received 31 July 2019

Revised 19 February 2020

Accepted 06 March 2020

Check for updates

(c) Author(s) (or their employer(s)) 2020. Re-use permitted under CC BY-NC. No commercial re-use. See rights and permissions. Published by BMJ.

${ }^{1}$ Center for Community-Based Healthcare Research and Education (CoHRE), Organization for Research and Academic Information, Shimane University, Izumo, Shimane, Japan ${ }^{2}$ Center for Primary Health Care Research, Lund University, Malmö, Sweden

${ }^{3}$ Department of Sports Sociology and Health Sciences, Faculty of Sociology, Kyoto Sangyo University, Kita-ku, Kyoto, Japan ${ }^{4}$ Faculty of Human Sciences, Shimane University, Matsue,

Shimane, Japan

${ }^{5}$ Department of Functional Pathology, Faculty of Medicine, Shimane University, Izumo, Shimane, Japan

Correspondence to

Dr Takafumi Abe;

t-abe@med.shimane-u.ac.jp

\section{ABSTRACT}

Objectives We investigated whether a moderate-tovigorous physical activity (MVPA) level and walking time were associated with a hilly environment in rural Japanese older adults.

Design Cross-sectional study.

Setting Unnan city, Ohnan and Okinoshima towns in Shimane, Japan.

Participants Data were collected from 1115 adults from the Shimane CoHRE study, who were aged 60 years and older and living in rural Japan in 2012.

Measures We measured the total time spent on MVPA and walking using a Japanese short version of the International Physical Activity Questionnaire. The land slope in 400 or $800 \mathrm{~m}$ network buffers was assessed using the geographic information system. A multivariable Poisson regression model examined the prevalence ratios $(\mathrm{PR})$ and $95 \%$ Cls of walking time or MVPA levels meeting the WHO guideline ( $\geq 150 \mathrm{~min} /$ week) in the land slope categories (low, middle and high), adjusted for confounders.

Results Engaging in the recommended level of MVPA was significantly associated with middle land slope $(P R=1.07$; $p=0.03)$ and high land slope ( $P R=1.06 ; p=0.07)$ compared with low land slope in the $400 \mathrm{~m}$ network buffer, as well as with middle land slope $(P R=1.02 ; p=0.48)$ and high land slope $(P R=1.04 ; p=0.25)$ compared with the low land slope in the $800 \mathrm{~m}$ network buffer. Walking time was significantly associated with middle land slope $(P R=1.13$; $p=0.04)$ and high land slope ( $P R=1.17 ; p=0.01)$ compared with low land slope in the $400 \mathrm{~m}$ network buffer, and with middle land slope $(P R=1.09 ; p=0.16)$ and high land slope $(P R=1.17 ; p<0.01)$ compared with low land slope in the $800 \mathrm{~m}$ network buffer. The sensitivity analysis found only a positive association between walking time and land slope in the 400 and $800 \mathrm{~m}$ network buffers.

Conclusions This study showed that a hilly environment was positively associated with walking time among older adults living in rural Japan.

\section{INTRODUCTION}

Moderate-to-vigorous physical activity (MVPA) in older adults has important health benefits. ${ }^{1-3}$ The WHO recommended that older adults should engage in at least $150 \mathrm{~min}$ of moderate intensity physical activity throughout the week, or at least $75 \mathrm{~min}$ of vigorous intensity physical activity throughout

\section{Strengths and limitations of this study}

Residential land slope was examined using objective measures based on the home address.

- This cross-sectional study cannot identify causal relationships.

- Self-reported physical activity may be influenced by recall bias.

- The study participants were enrolled in an annual health examination, which might have led to selection bias.

- This is the first study to examine the neighbourhood environment for older adults in rural Japan, which is facing rapid population ageing.

the week or an equivalent combination of moderate and vigorous intensity physical activity. ${ }^{1}$ However, globally, older adults do not get enough physical activity. ${ }^{4}$ Despite the positive health benefits associated with regular physical activity, inactivity remains a common public health problem.

Physical environment correlates for older adults' physical activity include neighbourhood walkability, which is combined with residential density, street connectivity, land use mix and retail floor ratio. ${ }^{5}$ Recent systematic reviews showed that these correlates have a strong and consistent association with older adults' physical activity. ${ }^{6} 7$ However, these reviews included mostly western urban settings. These urban environmental correlates were not thought to be associated with walking in the rural population, ${ }^{89}$ and were rarely applicable to assessing rural environments. ${ }^{10}$ Therefore, research focusing on a rural environment is needed.

Hilly environments are a typical feature of Japanese cities and suburbs, ${ }^{11}$ with $72.8 \%$ of the country's land area being mountainous or hilly and only $14 \%$ considered flat (eg, less than $3 \%$ slope). ${ }^{12}$ Previous studies have reported that a hilly environment was positively associated with hypertension ${ }^{13}$ 
and weight gain. ${ }^{14}$ By contrast, a hilly environment was reported to be negatively associated with diabetes. ${ }^{15} 16$ Results on health outcomes have been inconsistent. For physical activity, two recent systematic reviews reported a total of 172 studies on environmental variables among older adults, ${ }^{67}$ reporting that objectively measured land slope was an environmental variable used in six studies. According to these reviews, too few studies have been conducted to draw conclusions regarding the association between land slope as an environmental attribute and leisure-time physical activity outcomes. The reviews included only one study in the mixed (urban and rural) setting, which reported that land slope was positively associated with walking and negatively associated with sports activity in rural areas. ${ }^{17}$ However, land slope in urban areas was not associated with walking. ${ }^{17}$ To clearly identify positive associations between land slope and older adults' physical activity, including walking, further studies are needed. To the best of our knowledge, no previous studies have examined whether a hilly environment is associated with the WHO-recommended MVPA levels and walking among older adults in a rural community setting. We hypothesised that hilly rural residents are more likely to meet the recommended MVPA levels because walking up and down slopes is more physically demanding than walking on the flat. ${ }^{18}$ In addition, if we postulate that selfreported MVPA is positively associated with a hilly environment, we expect to clarify the relationship, hitherto inconsistent across studies, between a hilly environment and walking as a moderate-intensity activity in MVPA. This study aimed to examine whether an objectively measured hilly environment was positively associated with older Japanese rural adults' self-reported MVPA levels or walking.

\section{MATERIALS AND METHODS Participants}

This cross-sectional study was part of a cohort study in Shimane, a rural prefecture in Japan (the Shimane CoHRE Study). Data were collected from health examinations conducted in Shimane from June to November 2012. Participant inclusion criteria were: aged 60 years or older, community-dwelling and health examination. In all, 1880 adults aged 60 years or older participated in the health examinations. Informed consent was obtained from all participants before enrolment. After excluding participants with missing data (MVPA and sedentary time (ST), $n=125$; years of education, $n=632$; and geographic information system (GIS) code, $n=8$ ), we analysed the complete data from 1115 participants. There were no significant differences in gender $(\mathrm{p}=0.72)$, age $(\mathrm{p}=0.06)$ or body mass index (BMI) ( $\mathrm{p}=0.32)$ between the participants with missing data and those with complete data. These data are not shown.

\section{Outcome variables}

Self-reported MVPA was evaluated using the short version of the International Physical Activity Questionnaire
(IPAQ-SV).$^{19} 20$ Test-retest reliability and criterion validity of the Japanese version of the IPAQ-SV were confirmed. ${ }^{21}$ Total time spent on MVPA was calculated from participant reports on the frequency and duration of three types of physical activity (PA) (vigorous or moderate intensity without walking, and walking) by their metabolic equivalents (METs) (vigorous intensity PA (VPA)=8.0 METs; moderate intensity PA $(\mathrm{MPA})=4.0$ METs and walking $=3.3$ METs) to obtain estimated energy expenditure in MET hours/week. Using these values, total MVPA was defined as 7 days $\times$ (8.0 METs $\times$ VPA hours/day+4.0 METs $\times$ MPAhours/ day+3.3 METs $\times$ walking hours/day). We divided the results into two categories using a cut-off value $(\geq 8.25$ METs/ week) based on the current MVPA recommendations ( $\geq 150 \mathrm{~min} /$ week). ${ }^{1}$ Walking time was also divided into two categories using a previous study's cut-off ( $\geq 150 \mathrm{~min} /$ week). ${ }^{22}$

\section{Exposure variables}

We used land slope, which expresses a neighbourhood's hilliness, ${ }^{1417}$ as a primary exposure variable within 400 and $800 \mathrm{~m}$ network buffers from each participant's residence. A network buffer is a polygonal geometric space which approximates the daily activity space of each participant along with the actual street network. We set multiple network buffers, 400 and $800 \mathrm{~m}$, which were found to be appropriate activity spaces for people in previous neighbourhood studies. ${ }^{23} 24$ The buffer zones were computed along with actual street network, which excluded nonhabitable areas, such as forests, rivers and mountains. The mean land slope was retrieved from the elevation and Degree of Slope 5th Mesh Data (as of 2011). The Degree of Slope 5th Mesh Data consist of a number of $50 \times 50 \mathrm{~m}$ grid squares, each of which stores the land slope value. We computed the mean land slope within each network buffer for the grid squares which intersect with a buffer. These data were obtained from publicly available GIS data administered by the National Land Information Division, National Spatial Planning and Regional Policy Bureau of Japan. All spatial analyses were conducted using ArcGIS V.10.0. We calculated three categories (low, middle and high) of land slope that was divided into tertiles in the 400 or $800 \mathrm{~m}$ network buffers, respectively (table 1 ).

\section{Covariates}

Gender (man or woman) and age (in years, coded as a categorical variable), disease treatment (eg, medicine for hypertension, dyslipidaemia or diabetes), residential town/ city (Okinoshima town, Ohnan town or Unnan city) and years of education $(\geq 12$ years or $<12$ years) were collected through face-to-face interviews conducted by trained staff. Height and weight were measured by public health nurses. BMI was calculated by measured height and weight data in $\mathrm{kg} / \mathrm{m}^{2}$ and divided into three categories using Asian cutoffs (underweight: $<18.5 \mathrm{~kg} / \mathrm{m}^{2}$; normal: $18.5-22.9 \mathrm{~kg} / \mathrm{m}^{2}$; overweight: $\left.\geq 23.0 \mathrm{~kg} / \mathrm{m}^{2}\right) .{ }^{25} \mathrm{ST}$ was estimated by the total time spent on sedentary behaviour per day using IPAQ-SV as follows: (ST on weekdays $\times 5+\mathrm{ST}$ on weekends $\times 2$ ) $/ 7$, 
Table 1 Land slope characteristics

\begin{tabular}{|c|c|c|c|c|c|c|c|c|}
\hline \multirow[b]{2}{*}{ Network buffer } & \multicolumn{2}{|l|}{ Total } & \multicolumn{2}{|c|}{ Okinoshima town } & \multicolumn{2}{|c|}{ Ohnan town } & \multicolumn{2}{|c|}{ Unnan City } \\
\hline & $400 m$ & $800 \mathrm{~m}$ & $400 m$ & $800 \mathrm{~m}$ & $400 \mathrm{~m}$ & $800 \mathrm{~m}$ & $400 \mathrm{~m}$ & $800 \mathrm{~m}$ \\
\hline Minimum & 1.2 & 2.1 & 4.0 & 4.8 & 2.9 & 3.4 & 1.2 & 2.1 \\
\hline Mean & 9.8 & 11.0 & 9.3 & 11.3 & 10.2 & 11.5 & 9.4 & 10.2 \\
\hline SD & 4.7 & 4.8 & 2.9 & $\underline{3.3}$ & 4.9 & 5.2 & 4.8 & 4.5 \\
\hline \multicolumn{9}{|l|}{ Tertile } \\
\hline Lower & 7.4 & 8.2 & 7.8 & 10.0 & 7.4 & 8.2 & 6.8 & 7.5 \\
\hline Upper & 11.5 & 13.1 & 10.7 & 12.9 & 12.1 & 14.0 & 11.1 & 12.4 \\
\hline
\end{tabular}

and divided into two categories: 'low ST' ( $<3$ hours/day) or 'high ST' ( $\geq 3$ hours/day) using cut-off values from the median.

\section{Statistical analyses}

Descriptive statistics were calculated for all variables by MVPA group (met guidelines and did not meet guidelines) or walking time group. Between-group differences were determined using a $\chi^{2}$ test for categorical variables. Multivariate-adjusted Poisson regression analyses were conducted to estimate the prevalence ratios (PR) and 95\% CIs for MVPA or walking time category by land slope category for 400 and $800 \mathrm{~m}$ network buffers. Analyses were performed with an unadjusted model (Model 1), a model adjusted for gender, age and BMI as confounding factors (Model 2) and a model adjusted for Model 2 results, ST, disease treatment, years of education, and residential town/ city as confounding factors (Model 3). Before conducting the Poisson regression, we assessed correlations among variables to examine multicollinearity. There were no high correlations, so we determined that multicollinearity was not a factor $(r<0.21$, data not shown). For the sensitivity analysis, Poisson regression analysis was used to examine MVPA or walking time with land slope that included participants ( $\mathrm{n}=986)$ in Ohnan town and Unnan city (mainland only). Okinoshima town is on an island, and, therefore, land slope character is different from that on the mainland (as in Ohnan town and Unnan city). In Okinoshima town, the maximum value of land slope in each network buffer is the lowest of the three locations (table 1). All statistical analyses were conducted using IBM SPSS Statistics V.24.0 for Windows. For all analyses, $\mathrm{p}$ values less than 0.05 were considered statistically significant.

\section{Patient and public involvement}

No patients were involved.

\section{RESULTS}

Table 2 displays participants' characteristics. Overall, 84.8\% of the older Japanese adults in our sample met the recommended level of MVPA. There were significant differences in the prevalence of MVPA recommended levels by gender $(\mathrm{p}=0.05)$, age $(\mathrm{p}=0.08)$, BMI $(\mathrm{p}=0.17), \mathrm{ST}(\mathrm{p}=0.67)$, disease treatment $(\mathrm{p}=0.18)$, residential town $/$ city $(\mathrm{p}<0.01)$ and years of education $(\mathrm{p}=0.19)$. There were significant differences in walking time for gender $(\mathrm{p}=0.84)$, age $(\mathrm{p}<0.01)$, BMI $(\mathrm{p}=0.39)$, ST $(\mathrm{p}=0.39)$, disease treatment $(\mathrm{p}=0.85)$, residential town/city $(\mathrm{p}=0.26)$ and years of education $(\mathrm{p}=0.16)$.

Table 3 shows the results of the Poisson regression exploring the associations between MVPA category (met or did not meet recommendation), walking time and the hilly environment variables. After adjusting for all confounders (Model 3), meeting the recommended MVPA level was associated with middle land slope $(\mathrm{PR}=1.07 ; \mathrm{p}=0.03)$ and high land slope $(\mathrm{PR}=1.06 ; \mathrm{p}=0.07)$ compared with low land slope in the $400 \mathrm{~m}$ network buffer ( $\mathrm{p}$ for trend $=0.07$ ), and middle land slope $(\mathrm{PR}=1.02 ; \mathrm{p}=0.48)$ and high land slope $(\mathrm{PR}=1.04 ; \mathrm{p}=0.25)$ compared with low land slope in the $800 \mathrm{~m}$ network buffer ( $\mathrm{p}$ for trend=0.25). After adjusting for all confounders (Model 3), walking time was associated with middle land slope $(\mathrm{PR}=1.13 ; \mathrm{p}=0.04)$ and high land slope $(\mathrm{PR}=1.17 ; \mathrm{p}=0.01)$ compared with low land slope in the $400 \mathrm{~m}$ network buffer ( $\mathrm{p}$ for trend $=0.01$ ), and middle $(\mathrm{PR}=1.09 ; \mathrm{p}=0.16)$ and high $(\mathrm{PR}=1.17 ; \mathrm{p}<0.01)$ land slope compared with low land slope in the $800 \mathrm{~m}$ network buffer ( $\mathrm{p}$ for trend $<0.01$ ).

The sensitivity analysis yielded similar results to the main analysis (online supplementary eTable 1). After adjusting for all confounders, MVPA level was not associated with middle $(\mathrm{PR}=1.06 ; \mathrm{p}=0.07)$ or high $(\mathrm{PR}=1.05 ; \mathrm{p}=0.12)$ land slope compared with low land slope in the $400 \mathrm{~m}$ network buffer ( $\mathrm{p}$ for trend $=0.19$ ) or with middle $(\mathrm{PR}=1.02 ; \mathrm{p}=0.49$ ) or high $(\mathrm{PR}=1.04 ; \mathrm{p}=0.21)$ land slope compared with low land slope in the $800 \mathrm{~m}$ network buffer ( $\mathrm{p}$ for trend $=0.31$ ). However, walking time was associated with middle land slope $(\mathrm{PR}=1.14 ; \mathrm{p}=0.05)$ and high land slope $(\mathrm{PR}=1.18$; $\mathrm{p}=0.01$ ) compared with low land slope in the $400 \mathrm{~m}$ network buffer ( $\mathrm{p}$ for trend $=0.03)$, and middle land slope $(\mathrm{PR}=1.10$; $\mathrm{p}=0.14)$ and high land slope $(\mathrm{PR}=1.20 ; \mathrm{p}<0.01)$ compared with low land slope in the $800 \mathrm{~m}$ network buffer ( $p$ for trend $<0.01)$.

\section{DISCUSSION}

To the best of our knowledge, this study is the first to examine associations between a hilly environment and 
Table 2 Participants' characteristics

\begin{tabular}{|c|c|c|c|c|c|c|c|}
\hline \multirow[b]{2}{*}{ Variables } & \multirow[b]{2}{*}{ Total } & \multicolumn{3}{|c|}{ MVPA meeting guidelines } & \multicolumn{3}{|c|}{ Walking time } \\
\hline & & Not meeting & Meeting & & $\begin{array}{l}<150 \mathrm{~min} / \\
\text { week }\end{array}$ & $\begin{array}{l}\geq 150 \mathrm{~min} / \\
\text { week }\end{array}$ & \\
\hline n (\%) & 1115 & $170(15.2)$ & $945(84.8)$ & P value* & $428(38.6)$ & $687(61.6)$ & P value* \\
\hline \multicolumn{8}{|l|}{ Gender } \\
\hline Men & $431(38.7)$ & $54(12.5)$ & $377(87.5)$ & 0.05 & $167(38.7)$ & $264(61.3)$ & 0.84 \\
\hline Women & $684(61.3)$ & $116(17.0)$ & $568(83.0)$ & & $261(38.2)$ & $423(61.8)$ & \\
\hline \multicolumn{8}{|l|}{ Age } \\
\hline $60-69$ years old & $447(40.1)$ & $70(15.7)$ & 377 (84.3) & 0.08 & $188(42.1)$ & 259 (57.9) & $<0.01$ \\
\hline $70-79$ years old & $592(53.1)$ & $82(13.9)$ & $510(86.1)$ & & $203(34.3)$ & $389(65.7)$ & \\
\hline 80 years old and above & $76(6.8)$ & $18(23.7)$ & $58(76.3)$ & & 37 (48.7) & 39 (51.3) & \\
\hline \multicolumn{8}{|l|}{ Body mass index (Asian cut-off) } \\
\hline Under weight, $<18.5$ & $79(7.1)$ & $17(21.5)$ & $62(78.5)$ & 0.17 & $36(45.6)$ & $43(54.4)$ & 0.39 \\
\hline Normal weight, 18.5-22.9 & $594(53.3)$ & $82(13.8)$ & $512(86.2)$ & & $223(37.5)$ & $371(62.5)$ & \\
\hline Over weight, $\geq 23.0$ & $442(39.6)$ & $71(16.1)$ & $371(83.9)$ & & $169(38.2)$ & $273(61.8)$ & \\
\hline \multicolumn{8}{|l|}{ Sedentary time } \\
\hline$\geq 3$ hours/day & 646 (57.9) & $101(15.6)$ & 545 (84.4) & 0.67 & 241 (37.3) & 405 (62.7) & 0.39 \\
\hline$<3$ hours/day & $469(42.1)$ & $69(14.7)$ & $400(85.3)$ & & $187(39.9)$ & $28260.1)$ & \\
\hline \multicolumn{8}{|l|}{ Disease treatment } \\
\hline No & $564(50.6)$ & $78(13.8)$ & $486(86.2)$ & 0.18 & $218(38.7)$ & 346 (61.3) & 0.85 \\
\hline Yes & $551(49.4)$ & $92(16.7)$ & 459 (83.3) & & $210(38.1)$ & 341 (61.9) & \\
\hline \multicolumn{8}{|l|}{ Residential area } \\
\hline Okinoshima town & 129 (11.6) & 38 (29.5) & $91(70.5)$ & $<0.01$ & $57(44.2)$ & $72(55.8)$ & 0.26 \\
\hline Ohnan town & $563(50.5)$ & $70(12.4)$ & $493(87.6)$ & & $206(36.6)$ & $357(63.4)$ & \\
\hline Unnan city & 423 (37.9) & $62(14.7)$ & 361 (85.3) & & 165 (39.0) & $258(61.0)$ & \\
\hline \multicolumn{8}{|l|}{ Years of education } \\
\hline$\geq 12$ years & $499(44.8)$ & $84(16.8)$ & 415 (83.2) & 0.19 & $203(40.7)$ & 296 (59.3) & 0.16 \\
\hline$<12$ years & 616 (55.2) & $86(14.0)$ & $530(86.0)$ & & 225 (36.5) & 391 (63.5) & \\
\hline
\end{tabular}

*Statistical significance of the differences between groups was determined using $\chi 2$ test for categorical data. Bold shows significance $p<0.05$.

WHO recommended MVPA levels and walking time among older adults living in rural areas of Japan. We found a positive relationship between the hilly environments and PA among older Japanese adults. In particular, walking had a positive relationship with the hilly environment. The results from sensitivity analyses supported the main analyses findings, suggesting that a hilly environment is more strongly associated with walking time than the residential area (town/city). Adding to previous reviews that showed inconsistent relationships between land slope and physical activity, ${ }^{67}$ our results contributed solid findings regarding positive relationships between self-reported walking, and objectively measured land slope. Barnett's meta-analysis showed that objectively measured hills as physical environmental barriers were positively associated with total physical activity among older adults. ${ }^{6}$ However, subjectively measured physical environmental barriers were not associated with total physical activity. These results suggest that objectively and subjectively measured land slope has different effects on physical activity levels. ${ }^{6}$ Although our study did not examine participants' subjective evaluations of their physical environment, our results support the finding that objectively measured hilliness was associated with walking intensity level.

Systematic reviews revealed only one study that examined land slope as an objective environmental barrier in rural setting designs. ${ }^{6}$ Hanibuchi et al reported a positive association between land slope and walking among older people living in a rural area. ${ }^{17}$ Our findings supported this result. We speculated that the mechanism of the relationship between living in a rural hilly environment and engaging in sufficient walking, that is, $150 \mathrm{~min} /$ week in this study, is threefold. First, a hilly environment tends to have beautiful scenery that may encourage older people to walk. ${ }^{22}{ }^{26}$ They might walk for recreational purposes as well as for transport when they live in attractive environments. ${ }^{22}$ Dadpour's review concluded that enjoying 


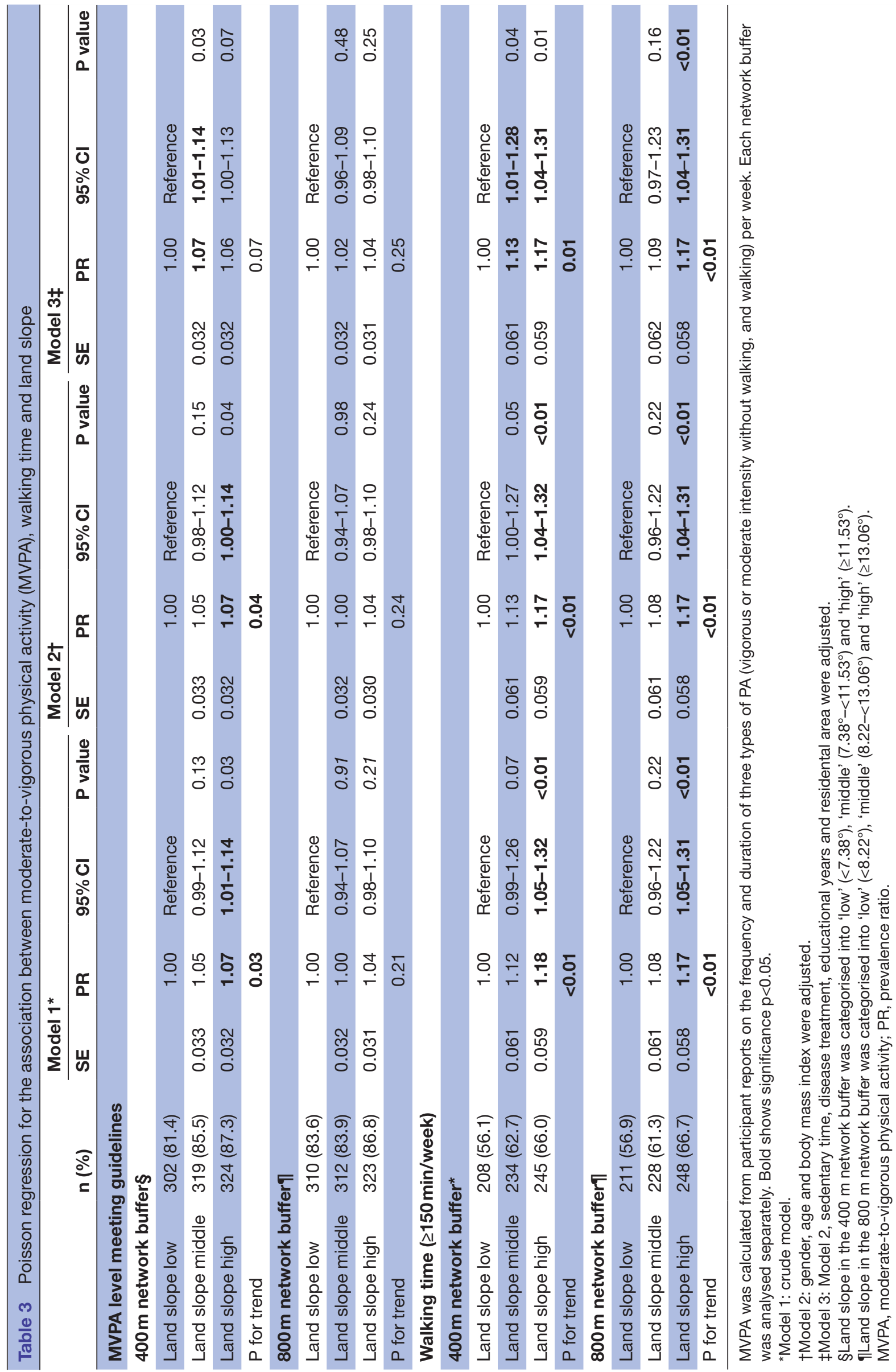


natural elements along the way encouraged spending more time walking and selecting longer routes for walking. In addition, relaxation and the joy of observing nature decreased the speed of walking and increased the time spent walking. ${ }^{27}$ Second, flatter rural areas often include long stretches of road with few people and high speed traffic. Poor sidewalks and traffic safety might discourage walking. ${ }^{28}{ }^{29}$ If older people perceive danger from a poor sidewalk or traffic, they may be less receptive to physical activity such as walking. Third, an older adult who has lived and worked in hilly terrain for a lifetime may be less likely to perceive such terrain as a barrier than one who has lived in flatter terrain. For the elderly, the same neighbourhood environment objectively and subjectively assessed might not have high consistency with PA. ${ }^{60}$ However, we did not measure the perceived environment; a mixed methodology is needed to further explore this complex issue.

This study has several limitations. First, it used a crosssectional design and, therefore, we could not infer causality between the hilly environment and MVPA. It is possible that older adults with poorer physical functioning may choose to live in less hilly areas, so there could actually be reverse causality. Second, sampling took place in multiple centers and recruited study participants from an annual health examination, which may have resulted in selection bias. Third, MVPA, including walking time, was measured using self-report questionnaires, which may have overestimated or underestimated MVPA or walking time as a result of response bias. In addition, this study did not include other types of MVPA (eg, farming activities) in the self-report questionnaire. Thus, MVPA factors need to be examined further in future research. Fourth, we did not measure participants' subjective sense of their physical environment or their recognition of the objective physical environment. Finally, we could not account for any effects of unmeasured factors that may have influenced the relationship between hilly environments and MVPA, such as rural/urban differences, socioeconomic status, poor health status or motor function. ${ }^{6731} 32$

\section{CONCLUSION}

We examined whether objectively measured hilly environments were associated with self-reported walking time and MVPA levels meeting the WHO recommendation in older rural Japanese adults. We found a positive relationship between the hilly environment and $P A$ in our study participants.

Contributors TA and KO: study concept and design, statistical analysis and drafting of the manuscript. TH, MT and MI: acquisition and interpretation of data. TH and TN: critical revision of the manuscript for important intellectual content. MI and TN: study supervision.

Funding This work was supported by JSPS KAKENHI Grant Number 18K111431B and $19 \mathrm{H} 03996$.

Competing interests None declared.

Patient and public involvement Patients and/or the public were not involved in the design, or conduct, or reporting, or dissemination plans of this research.
Patient consent for publication Not required.

Ethics approval The study protocol was approved by the Ethics Committee of Shimane University (\#2888). Informed consent was obtained from all participants before enrolment.

Provenance and peer review Not commissioned; externally peer reviewed.

Data availability statement Data are available upon reasonable request. This study used data from the Shimane CoHRE (Center for Community-Based Healthcare Research and Education) study. Some of the data are available from the CoHRE, Organization for Research and Academic Information, Shimane University, 223-8 Enya-cho, Izumo-shi, Shimane 693-8501, Japan.

Open access This is an open access article distributed in accordance with the Creative Commons Attribution Non Commercial (CC BY-NC 4.0) license, which permits others to distribute, remix, adapt, build upon this work non-commercially, and license their derivative works on different terms, provided the original work is properly cited, appropriate credit is given, any changes made indicated, and the use is non-commercial. See: http://creativecommons.org/licenses/by-nc/4.0/.

ORCID iD

Takafumi Abe http://orcid.org/0000-0001-8657-4707

\section{REFERENCES}

1 World Health Organization. WHO guidelines Approved by the guidelines review Committee. Global recommendations on physical activity for health. Geneva: World Health Organization, 2010.

2 Chodzko-Zajko WJ, Proctor DN, American College of Sports Medicine. American College of sports medicine position stand. exercise and physical activity for older adults. Med Sci Sports Exerc 2009;41:1510-30.

3 Lee I-M, Shiroma EJ, Lobelo F, et al. Effect of physical inactivity on major non-communicable diseases worldwide: an analysis of burden of disease and life expectancy. Lancet 2012;380:219-29.

4 Guthold R, Stevens GA, Riley LM, et al. Worldwide trends in insufficient physical activity from 2001 to 2016: a pooled analysis of 358 population-based surveys with 1.9 million participants. Lancet Glob Health 2018;6:e1077-86.

5 Frank LD, Schmid TL, Sallis JF, et al. Linking objectively measured physical activity with objectively measured urban form: findings from SMARTRAQ. Am J Prev Med 2005;28:117-25.

6 Barnett DW, Barnett A, Nathan A, et al. Built environmental correlates of older adults' total physical activity and walking: a systematic review and meta-analysis. Int J Behav Nutr Phys Act 2017;14:103.

7 Van Cauwenberg J, Nathan A, Barnett A, et al. Relationships between neighbourhood physical environmental attributes and older adults' leisure-time physical activity: a systematic review and metaanalysis. Sports Med 2018;48:1635-60.

8 Berry NM, Coffee NT, Nolan R, et al. Neighbourhood environmental attributes associated with walking in South Australian adults: differences between urban and rural areas. Int J Environ Res Public Health 2017;14:965.

9 Koohsari MJ, Sugiyama T, Shibata A, et al. Associations of street layout with walking and sedentary behaviors in an urban and a rural area of Japan. Health Place 2017;45:64-9.

10 Frost SS, Goins RT, Hunter RH, et al. Effects of the built environment on physical activity of adults living in rural settings. Am J Health Promot 2010;24:267-83.

11 Koohsari MJ, Nakaya T, Oka K. Activity-Friendly built environments in a Super-Aged Society, Japan: current challenges and toward a research agenda. Int J Environ Res Public Health 2018;15:E2054.

12 Statistics Bureau of Japan. Chapter 1 land and climate, 1- 6 area by configuration, gradient and prefecture. In: Historical statistics of Japan. Statistics Bureau of Japan, 2012. https://www.stat.go.jp/ english/data/chouki/01.html

13 Oka M, Yamamoto M, Mure K, et al. Relationships between lifestyle, living environments, and incidence of hypertension in Japan (in men): based on participant's data from the nationwide medical Check-Up. PLoS One 2016;11:e0165313.

14 Okuyama K, Abe T, Hamano T, et al. Hilly neighborhoods are associated with increased risk of weight gain among older adults in rural Japan: a 3-years follow-up study. Int $J$ Health Geogr 2019;18:10.

15 Villanueva K, Knuiman M, Koohsari MJ, et al. People living in hilly residential areas in metropolitan Perth have less diabetes: spurious association or important environmental determinant? Int $\mathrm{J}$ Health Geogr 2013;12:59. 
16 Fujiwara T, Takamoto I, Amemiya A, et al. Is a hilly neighborhood environment associated with diabetes mellitus among older people? results from the JAGES 2010 study. Soc Sci Med 2017;182:45-51.

17 Hanibuchi T, Kawachi I, Nakaya T, et al. Neighborhood built environment and physical activity of Japanese older adults: results from the Aichi Gerontological evaluation study (AGEs). BMC Public Health 2011:11:657.

18 Ainsworth BE, Haskell WL, Herrmann SD, et al. 2011 compendium of physical activities: a second update of codes and MET values. Med Sci Sports Exerc 2011;43:1575-81.

19 Craig CL, Marshall AL, Sjöström M, et al. International physical activity questionnaire: 12 -country reliability and validity. Med Sci Sports Exerc 2003;35:1381-95.

20 Tomioka K, Iwamoto J, Saeki K, et al. Reliability and validity of the International physical activity questionnaire (IPAQ) in elderly adults: the Fujiwara-kyo study. J Epidemiol 2011;21:459-65.

21 Murase N. Validity and reliability of Japanese version of international physical activity questionnaire. J Health Welfare Stat 2002;49:1-9.

22 Inoue S, Ohya Y, Odagiri Y, et al. Perceived neighborhood environment and walking for specific purposes among elderly Japanese. J Epidemiol 2011;21:481-90.

23 Mavoa S, Bagheri N, Koohsari MJ, et al. How do neighbourhood definitions influence the associations between built environment and physical activity? Int J Environ Res Public Health 2019;16:E1501.

24 Etman A, Kamphuis CBM, Pierik FH, et al. Residential area characteristics and disabilities among Dutch community-dwelling older adults. Int J Health Geogr 2016;15:42.
25 WHO Expert Consultation. Appropriate body-mass index for Asian populations and its implications for policy and intervention strategies. Lancet 2004;363:157-63.

26 Saito Y, Oguma Y, Inoue S, et al. Environmental and individual correlates of various types of physical activity among communitydwelling middle-aged and elderly Japanese. Int $J$ Environ Res Public Health 2013;10:2028-42.

27 Dadpour S, Pakzad J, Khankeh H. Understanding the influence of environment on adults' walking experiences: a meta-synthesis study. Int J Environ Res Public Health 2016;13:731.

28 Osama A, Sayed T. Evaluating the impact of connectivity, continuity, and topography of sidewalk network on pedestrian safety. Accid Anal Prev 2017;107:117-25.

29 Strath S, Isaacs R, Greenwald MJ. Operationalizing environmental indicators for physical activity in older adults. J Aging Phys Act 2007:15:412-24.

30 Brownson RC, Hoehner CM, Day K, et al. Measuring the built environment for physical activity: state of the science. Am J Prev Med 2009;36:S99-123.e12.

31 Huang S-J, Hung W-C, Sharpe PA, et al. Neighborhood environment and physical activity among urban and rural schoolchildren in Taiwan. Health Place 2010;16:470-6.

32 Bauman AE, Reis RS, Sallis JF, et al. Correlates of physical activity: why are some people physically active and others not? Lancet 2012;380:258-71. 